\title{
NOTAS SOBRE LA NORMATIVA JURÍDICA MUSULMANA APLICADA ENTRE LOS SARRACENOS DE LA RIBERA D'EBRE (TARRAGONA). SIGLOS XII-XIV
}

Pascual Ortega

Las comunidades musulmanas de La Ribera d'Ebre catalana fueron sometidas por el conde barcelonés Ramón Berenguer IV a mediados del siglo XII. En un primer momento, las capitulaciones firmadas y otras concesiones otorgadas a los musulmanes les aseguraron el mantenimiento prácticamente total de sus prácticas y posesiones anteriores. La realidad fue, sin embargo, que la continua presión de los poderes cristianos provocó modificaciones sustanciales en diversos campos: fiscalidad, régimen de tenencia de la tierra, formas de organización, ámbitos efectivos de ejercicio de la administración de justicia por parte de los oficiales musulmanes, manifestaciones religiosas, etc. Todo ello forma parte del universo vital musulmán, por lo que las mutaciones sufridas constituyen un evidente y profundo proceso de aculturación ${ }^{1}$.

Uno de los aspectos más singulares de ese universo es la normativa jurídica que regía entre los miembros de la comunidad musulmana, rasgo básico de la identidad de ese grupo humano, de donde procede su relevancia. El derecho islámico "derivava directament de la revelació divina i indirectament de la seua interpretació vivent que va ser la vida de Mahoma"; de ahí que se consideren fuentes del derecho el Corán, como palabra de Dios, la zuna, práctica del profeta, y los hadices, compendio de visiones coetáneas sobre su comportamiento, transmitidas oralmente y luego puestas por escrito. A partir de tales fuentes se elaboraba la sarï'a, ley islámica, que los juristas

1. Estudiamos estos cambios en los capítulos y apartados correspondientes de nuestro trabajo La sociedad de las tierras del Ebre: El señorio templario y hospitalario de Ribera d'Ebre y Terra Alta (1150-1350), tesis doctoral (inédita), Universitat Rovira i Virgili, Tarragona, 1995. 
completaban basándose en el consenso comunitario y en razonamientos analógicos ${ }^{2}$.

Font Rius denominó "carta de seguridad" -por las primeras palabras del texto- al documento concesivo que Ramón Berenguer IV otorgó a los musulmanes de varios lugares de La Ribera d'Ebre en fecha incierta, pero entre 1153 y 1159, al poco de la conquista. Si bien contempla múltiples aspectos, el documento es parco en alusiones a las leyes o normas que utilizarían los musulmanes que decidieran permanecer en la zona; únicamente efectúa una referencia parcial a juicios y herencias, temas en que acepta la aplicación de leyes anteriores ${ }^{3}$. A la vista de ello, y dado que no hay mención global en sentido contrario, cabe suponer que en los demás aspectos también se seguirían aplicando las mismas leyes.

Desde luego, ésta es la conclusión que se extrae de las capitulaciones de Tortosa y Tudela, a las que remite claramente la carta de Ribera para todo lo que no esté contenido en ella 4 . Como resumen genérico, ambas, en efecto, afirman de manera taxativa que los musulmanes se regirán por sus propias leyes -con terminología diversa: fueri, iustitiae, zuna- y que sus jueces aplicarán las penas allí contempladas -castigamenti- ${ }^{5}$. En el mismo sentido se pronunciará a mediados del siglo XIII la carta firmada por la Orden del Hospital

2. R.I. BURNS, L'Islam sota els croats. Supervivència colonial en el segle XIII al Regne de València, València, 1990 (New Jersey, 1973), vol. I, p. 334.

3. J.M. Font RIUS, «La Carta de seguridad de Ramón Berenguer IV a las morerías de Ascó y Ribera del Ebro (siglo XII)», Homenaje a Don José María Lacarra de Miguel en su jubilación del profesorado, vol. I, 1977, pp. 261-283, y reed. en Estudis sobre els drets i institucions locals en la Catalunya medieval, Barcelona, 1985, pp. 561-576 (que es la versión que consultamos): “...et sint iudicia eorum el hereditaciones (?) eorum sicul est consueludo legis eorum"; en adelante, nos referimos a este texto como carta de seguridad o carta de Ribera, simplemente.

4. $\quad$ Carta de seguridad: "[Ramon Berenguer IV] Donat eis ut habeant tale furus quale habent in Caragoça et in Tortosa. Et de illa carta de Caragoça el de illo furo mutent et mutant in ista carta hoc quod non est in isla carta". Aunque no se menciona en el texto, añadimos la carta de Tudela debido a la identificación básica que existía entre ésta, la desconocida de Zaragoza y la de Tortosa, según opinión aceptada desde antiguo; véanse los comentarios de FONT, La Carta..., p. 563, siguiendo el estudio de RIBERA, Orígenes del justicia de Aragón, Zaragoza, 1897, p. 397 y ss., ap. II. La capitulación de Tortosa fue publicada por P. de BofArULl, CODOIN, vol. IV, pp. 130-134, pero la hemos consultado en F. FERNÁNDEZ, Estado social y político de los mudéjares de Castilla, Madrid, 1866 (reed.: Madrid, 1985), doc. V, pp. 299-301; y la carta de Tudela puede encontrarse en T. MUÑOZ, Colección de fueros municipales y cartas pueblas, Madrid, 1847 (reed.: Madrid, 1978), pp. 414-417 (quien la toma de REAL ACADEMIA DE LA HISTORIA, Diccionario Histórico-Geográfico de España, tomo II, p. 558) y en A. GARCÍA-GALLO, Manual de historia del Derecho Español, Madrid, 1984, vol. II, pp. 539-542, extraída del anterior. A partir de este momento nos referiremos a ellas como capitulación o convenio de Tortosa o Tudela, según corresponda.

5.

Capitulación de Tortosa: "Et totos illos mauros quod stent in lures fueros el in lures iustitias [...] et stet super illos lure indice cum suos castigamentos, sicut est in lure lege, el in vio de lure indicio". La carta de Tudela no dispone de una indicación tan clara y radical, pero, luego de dejar sentado que "sint et stent illos [musulmanes] in indicios el pleitos in manu de lure alcudi et de 
y los sarracenos traídos desde Silla (País Valencià) a L'Aldea, un lugar del término general de Tortosa, después de y como castigo por su participación en una rebelión ${ }^{6}$.

Los diversos vocablos utilizados se subsumen en uno, zuna, sin otros matices o distinciones desde el punto de vista islámico ${ }^{7}$. Para los documentos de la zona, este término constituye la representación simplificada por excelencia del conjunto de leyes islámicas que se había reconocido a los musulmanes vencidos y que afectaba, tal como era normal en el mundo islámico, a cualquier comportamiento de la persona. Con este significado de conjunto de leyes, de normas rectoras de la vida de la comunidad, pues, es como debemos entender las referencias a la zuna que aparecen desde los primeros momentos, ya sea en solitario ${ }^{8}$, ya en compañía de otros términos de alcance parecido en la terminología cristiana medieval ${ }^{9}$.

A partir del conjunto de menciones se pueden efectuar diversas consideraciones que ilustren cómo y hasta qué punto se modificó la normativa jurídica anterior. Ahora bien, dada nuestra falta de especialización en estos temas, el presente escrito se limita a recoger y ordenar las referencias documentadas y proponer algunos breves apuntes provisionales, deseando que todo ello

lures alguaziles, sicut in tempus de illos moros fuit", al tratar el tema de los posibles pleitos entre miembros de las dos religiones, afirma que el cadí debe juzgar al sarraceno secundum suam zunam.

6. J.M. FONT RIUS, Cartas de población y franquicia de Cataluña, vol. I, Madrid-Barcelona, 1969, doc. 303: 1258, II, 12: el juez musulmán, alamín, debe juzgar secundum zunam sarracenorum; si algún sarraceno no admite la sentencia dictada, podrá apelar al cadí de Tortosa, quien decidirá sobre el caso, y el alamín de L'Aldea ejecutará la sentencia, et hoc faciat et iudicet per zunam omni tempore.

7. Lo mismo ocurría en el País Valencià, bien que algunas cartas de población, pocas, incluyan la expresión açuna et exarea o xara; véase BURNS, L'Islam..., vol. I, p. 342.

8. 1216, VI, 1: ACA, Pergs., Jaume 1, n. 43 (tomado de R. ARGEMÍ, Els tagarins a la Ribera d'Ebre al segle XIII, Memòria de Llicenciatura (inèdita), Barcelona, 1972, ap.; publicado ahora por L. PAGAROLAS, Els templers de les terres de l'Ebre (Tortosa). De Jaume I fins a l'abolicib de l'Orde (1213-1312), tesis doctoral (inédita), Barcelona, 1990, ap., n. $\left.{ }^{\circ} 4\right)$ : el personaje nombrado ha de ser buen y recto cadí de omni zune Dertose y, si fuera acusado, será juzgado secundum zunam; 1282, VII, 22: ACA, R. 59, f. 46v. (tomado de ARGEMí, op. cit., ap.): el subveguer de Tortosa ha de actuar según la zuna en el asunto de una sarracena y su hijo, detenidos; 1317, XII, 5: AHN, BM, leg. 8261 ${ }^{2}$, n. ${ }^{\circ} 1$ (Carp. 610, n. ${ }^{\circ}$ 92): el alamín prestó juramento de fidelidad secundum dictam çunam; 1323, VI, 20: AHN, EA, leg. 8175, n. ${ }^{\circ} 10$ (Carp. 636, n. ${ }^{\circ}$ 19): el comendador hospitalario de Ascó manda que una sarracena fuera juzgada per çuna; 1332 , IX, 24: AHN, EA, leg. $8175^{1}$, n. $^{\circ} 11$ (Carp. 636, n. ${ }^{\circ}$ 20): los jurados consideran que una actuación del comendador es contra lur çuna; 1369, XI, 23: AHN, EA, leg. 8176, n. ${ }^{\circ} 13$ (Carp. 637, n. ${ }^{\circ}$ 28): los jurados musulmanes piensan que un sarraceno deu ésser jutjat per çuna; 1385, X, 22: AHN, Cód., 605-B, f. 82: licencia a un zabazala para que testifique contratos privados según zuna.

9. 1180, IX: ACA, Pergs., Alfons I, n. ${ }^{\circ} 299$ (tomado de ARgEMÍ, Els tagarins..., ap.): “illann zunam et consuetudinem et furum"; 1216, VI, 1: ACA, Pergs., Jaume I, n. ${ }^{\circ} 43$ (ARGEMÍ, íb., ap. y, ahora, PAGAROLAS, Els templers..., ap., n. ${ }^{\circ}$ 4): “zunam et morem sarracenorum”; 1282, XII, 1: ACA, R. 59, f. 173r. (ARGEMí, ib., ap.): "ius et çunam sarracenorum". 
pueda utilizarse en trabajos de mayor amplitud, entidad y precisión. Con este propósito ofrecemos sucesivamente las menciones relativas a la persona capacitada para escriturar contratos, la función demostrativa de tales escrituras, herencias, acidaques, juicios, apelaciones y penas imponibles, y acabamos con la posible existencia de matices locales o regionales de la legalidad islámica.

Existen algunas indicaciones relativas al contenido de la normativa aplicada o al de la normativa que debiera haberse aplicado en el territorio -ésta, según afirmaciones procedentes de las comunidades musulmanas-, un contenido que a veces se identifica o se relaciona de forma explícita e indudable con la zuna.

Las relaciones privadas -en terminología actual- son con mucha probabilidad el campo donde permanecieron más vivos los preceptos islámicos, al menos mientras que no afectaran a la autoridad feudal; precisamente por privadas, empero, es una afirmación difícil de comprobar a partir de documentación señorial.

En Benissanet, a finales del siglo XIV, las escrituras podían ser tomadas por el zabazala sólo, quien recibió licencia del castellán para hacerlo y testificarlas según zuna; no podemos asegurar que esta situación fuera generalizable -de ahí las puntualizaciones de tiempo y lugar-, ya que en otros momentos las condiciones eran más estrictas) ${ }^{10}$.

El contrato, instrumento justificativo importante, devenía imprescindible para ciertas actuaciones relacionadas con la Orden del Hospital $]^{11}$. Sin embargo, a través de los jurados, la aljama de Ascó aseveraba que la zuna no admitía que nadie fuera forzado por otra persona a enseñar el título que justificaba una posesión, en especial si el bien de que se trataba había sido poseído desde tiempos inmemoriales. Esta posición coincide con la que adoptaron y plasmaron por escrito los legisladores tortosinos del siglo XIII respecto a las posesiones de los musulmanes denominados exaricos antiguos ${ }^{12}$.

10. 1385, X, 22: AHN, Cód., 605-B, f. 82: el castellán de Amposta concede licencia a Mahoma Guaxqui, zabazala de Benissanet para que él y los futuros zabazalas pudieran tomar contratos y testificarlos según zuna, y que tuvieran valor; sin embargo, en 1327, X, 8: AHN, BM, leg. 8260², n. ${ }^{\circ} 12$ (Carp. 611, n. ${ }^{\circ} 105$ ), el mismo castellán exigía que la escritura hubiera sido hecha "per mà d'un scrivà christià e altre moro" para que surtiera determinados efectos (véase la nota siguiente).

11. 1327, X, 8: AHN, BM, leg. 8260², n. ${ }^{\circ} 12$ (Carp. 611, n. ${ }^{\circ}$ 705): en el contexto de un problema que exponemos más adelante, relativo a la huida de unos sarracenos de Miravet y Benissanet sin licencia del castellán, se afirma que las esposas sólo podrían conservar "aquell [bien mueble] que fo mes en scriptura pública per mà d'un scrivà christià e altre moro".

12.

1332, IX, 24: AHN, EA, leg. 8175¹ , nº 11 (Carp. 636, n 20): constituye una acción "contra lur çuna [...] que un sie forçat per senyor ni per altre de mostrar títol de sa possessió, majorment de cosa que aja poseyda de tant de temps que memòria [...]". Según el código de Costums de Tortosa, los 
Otras manifestaciones nos acercan al interesante tema de las herencias. Burns apunta ciertas expresiones de tres cartas de población valencianas -Alfàndec, Xivert y Eslida- y de unos privilegios locales -Quart-, confirma dos en 1279, que garantizaban las prácticas legales anteriores y, con ello, generaliza: "El que ens en diuen les cartes valencianas assegura de manera suficient que la substància del dret islàmic es va mantenir operativa en les seues aplicacions socials". De la misma forma, la carta de seguridad de Ribera permitía a los sarracenos de la zona que las "herencias se hagan según la costumbre de su ley"13.

La continuidad de la legalidad islámica que trasciende de tales textos parece ser negada, empero, por otras manifestaciones. El nombramiento de un cadí en Tortosa (1216) incluye un párrafo según el cual los señores de la ciudad, Temple y Montcada, que le designan, le conceden que pueda legar sus bienes a sus hermanos, hermanas y parientes, y ellos a él, especificando: "Tal como permite la zuna y la costumbre". El matiz final, ciertamente, fundamenta y justifica la concesión en la legalidad vigente, pero, a la vez, nos obliga a preguntarnos sobre el porqué de la licencia expresa; no podemos sustraernos a la idea de que ya estaba presente o en proceso de imposición una cierta práctica restrictiva de los poderes cristianos en torno a las herencias de los musulmanes $\mathrm{y}$, de ahí, la necesidad de distinguir y favorecer con la licencia citada a un oficial tan importante como el cadí ${ }^{14}$. Poco más de un siglo después (1327), en el contexto de una discusión sobre los bienes de unos sarracenos de Miravet y Benissanet huidos a los dominios del conde de

exaricos antiguos "no són tenguts que mostrens les cartes de les honors ne com hi són ne com no", refiriéndose a las heredades que habían conservado luego de la conquista de la ciudad por los cristianos (Consuetudines Dertusae, Llib. IV, Rúb. De emphiteotico iure). Atendiendo a un comentario del doctor Epalza, cabe señalar que la ausencia de registros de propiedad privada (especialmente en terrenos agrícolas) es característica de la jurisdicción musulmana; por su parte, las propiedades de cofradías o "fundaciones religiosas" solían reseñarse por escrito, pero más por las obligaciones contractuales que su usufructo comportaba que por el carácter de propiedad que esas inscripciones "notariales" suponían.

13. BURNS, L'Islam..., vol. I, pp. 341-342, deteniéndose en la complejidad aritmética que suponían los cálculos de las divisiones de bienes en el derecho hereditario, según el tratado de Ibn Jaldün, autor que trata el tema como si fuera una "disciplina en si mateixa", en la que destacaron los maliquíes hispánicos. Carta de seguridad: "[...] hereditaciones (?) eorum [sean] sicut est consuetudo legis eorum”; sin embargo, la lectura del término correspondiente a herencias no parece segura, a tenor del interrogante de Font Rius.

14. 1216, VI, 1: ACA, Pergs., Jaume I, n. 43 (tomado de ARGEMÍ, Els tagarins..., ap.; ahora, publicado también por PAGAROLAS, Els templers..., ap., n. ${ }^{\circ}$ 4): "Preterea, volumus et concedimus ut tu possis sorores et frates tuos el parentes heredes facere, et ipsi te, ut zuna et mos est. Por su parte, el doctor Epalza piensa que la afirmación del texto "trata de preservar a esa autoridad musulmana, y a sus descendientes y herederos, de expolios por parte de autoridades cristianas o de presiones de esas autoridades en favor de unos herederos contra otros, en contra de la ley musulmana" (es un comentario personal, que queremos agradecerle, igual que otras ideas e indicaciones sobre el presente escrito que tuvo la gentileza de enviarnos). 
Prades, una de las cláusulas del pacto firmado entre éste y el castellán de Amposta presenta nuevamente la posibilidad de que algún musulmán no pudiera testar, bien que no se ofrezca ninguna razón específica para tal hecho ${ }^{15}$.

Con posterioridad, las informaciones todavía son más significativas. A mediados del siglo XIV, el castellán se quedaba tierras por herencias de los moros muertos, cosa que también indican el capbreu de 1416 y el de finales de la centuria, éste con más detalles: el castellán recibirá "todos los bienes" de los sarracenos que mueran "sin heredero"; pese a ciertas dudas que suscita la interpretación de tales textos, permanece en pie el aspecto central de la cuestión, la apropiación de bienes por parte del máximo dignatario de la orden ${ }^{16}$. Desde un punto de vista más general, un tratado catalán medieval de derecho islámico escrito a principios del siglo XV también informa que "los crestians senyors de aquells [musulmanes] prenen los dits béns" del sarraceno muerto sin ascendientes ni descendientes ${ }^{17}$.

La justificación de estas apropiaciones sólo puede ser la presión ejercida por los feudales con la pretensión de imponer entre los musulmanes prácticas similares a las que ya padecían algunos grupos cristianos, como los mals usos denominados intéstia y exòrquia. Resulta interesante observar que el tratado de derecho citado supone una evidente cobertura legal para la apropiación cuando interpreta que el rey y los señores cristianos "eran como el 'Tesoro Público' (bayt al-mäl) o 'Casa de Déu'” y que por esa razón "podían suceder los bienes de un difunto muerto sin ascendencia ni descen-

15. 1327, X, 8: AHN, BM, leg. 8260², n. 12 (Carp. 611, n. ${ }^{\circ} 105$ ): si algún sarraceno, “en lo quas, emperò, hon los dits moros pogesen fer testament, leyxa, ho eren parentes ho proisnies ho altres, dels dits lochs de Miravet ho de Benicene, feyen hereus ho lexaven béns seens" a los huidos, se aplicaría el acuerdo que incluye el texto para otros casos (la cursiva es nuestra).

16. 1349, VIII, 12: AHN, Códs., n. ${ }^{\circ}$ 599-B, f. 115: cl castellán da licencia a su lugarteniente en la encomienda de Miravet para "vender todas aquellas teras a nos pertenecientes o pertenecer devientes por herencias de los moros muertos", sin más, por lo que desconocemos si la apropiación se debía a que no existían herederos, no había testamento o a cierta porción que pudiera percibir de cualquier herencia de sus vasallos musulmanes. Capbreu de 1495: AHN, BM, Libro núm. 159, f. 10r.: los jurados reconocen al castellán de Amposta que "omnia bona omnium sarracenorum dicti loci de Miravet qui moriuntur absque herede aliquo sunt acquisita incontinenti, morte eorum secuta, dicto reverendissimo domino castellano Emposte [...] absque contradictione aliqua cuiuscumque persone"; para una interpretación más completa de este texto debiéramos saber con seguridad si la expresión «sin heredero» se refería a una simple muerte intestada, a una exigencia de ciertos grados de parentesco con el fin de poder acceder a los bienes del difunto o a una conjunción de ambas. Esta misma exigencia ya se planteaba en el capbreu de 1416, más cercano a la época que trabajamos, aunque sin llegar a desarrollarla completamente: "Item, ha el senyor de los bienes [pequeño espacio en blanco] de los moros que mueren" (1416: AHN, Códs., n. ${ }^{\circ}$ 678-B, f. $6 \mathrm{v}$.$) .$

17. C. BARCELÓ (ed. e intr.), Un tratado catalán medieval de derecho islámico: El llibre de la Cuna e Xara dels moros, Córdoba, 1989; Cap. CXXXIII, «Perquè los senyós crestians prenen los béns, segons Costum d'Espanya» (pp. 33-34). 
dencia"; por consiguiente, es posible que los actos de los primeros feudales que pretendieran obtener los bienes de un sarraceno difunto se basaran en el "consejo de algún cadí que aplicó en esto [sucesiones] el criterio analógico", según piensa su editora ${ }^{18}$. Pero el resultado, la apropiación, es indiscutible, ya se tratara de un camino recorrido mediante la presión directa y abierta, ya lo fuera aprovechando determinados aspectos de la legalidad islámica.

Dos de los documentos nos ponen frente a temas de la institución matrimonial, en especial los acidaques, que forman parte de su núcleo central. Antes que nada, sintetizaremos brevemente el contenido de ambos textos.

Hacia el principio del segundo cuarto del siglo XIV, cierto número de sarracenos de Miravet y Benissanet se fueron a vivir a Tivissa, dominio del conde de Prades, sin licencia del castellán de Amposta, por lo que éste embargó todos sus bienes muebles e inmuebles. Las protestas que esta acción debió de originar comportaron una negociación entre ambos feudales que culminó en un pacto a tenor del cual los musulmanes huidos podrían conservar los bienes inmuebles durante año y medio y, pasado ese periodo, venderlos a otros miembros de su religión que fueran vasallos hospitalarios o devolverlos a la Orden del Hospital; de no hacerlo así, el castellán los volvería a embargar.

Junto a esta cláusula central se contemplaban diversas situaciones que requerían matizaciones, entre las cuales el caso de las esposas -no sabemos cuántas- que habían quedado en Miravet y Benissanet. Respecto a ellas se pactó que, si lo deseaban, pudieran irse a vivir con sus maridos -y entonces también se aplicaría el acuerdo anterior a sus posesiones muebles-, y que pudieran cobrar sus acidaques -"açidachs", "acidayx"- de los bienes que el castellán dejaba conservar a los sarracenos durante aquel periodo de tiempo, incluso de los inmuebles, antes de que los vendieran o devolvieran ${ }^{19}$.

Por otro lado, a mediados del último cuarto de la misma centuria, un escrito del castellán comunicaba al regente de la encomienda que dos sarracenos de Miravet, Azmet Polpiç y su yerno, se iban a Zaragoza llevándose la ropa de casa y los accidaques de sus mujeres; y con el mismo escrito le manda-

18. BARCELÓ, Un tratado..., pp. XII-XIII.

19. 1327, X, 8: AHN, BM, leg. $8260^{2}$, n. ${ }^{\circ} 12$ (Carp. 611, n. $\left.{ }^{\circ} 105\right)$. La posibilidad de cobrar los acidaques de los bienes inmuebles implicaba un nuevo problema, no de índole matrimonial exclusivamente, pero que merece la pena ser mencionado: suponiendo que las esposas tomaran alguna tierra en pago de los acidaques debidos, ¿quién podría recoger y apropiarse los frutos de ese año? El castellán (y el pacto) soslayan el problema traspasando a un convenio entre los jurados y los sarracenos huidos la decisión de si éstos, por "çuna o special covinença o per costum ho deuen aver", una consideración a tener en cuenta para la constatación de posibles particularidades regionales o locales. 
ba, suponemos que mediada denuncia o petición de parte, que los detuviera hasta tanto no se avinieran con sus mujeres, amigos o parientes de ellas ${ }^{20}$.

El vocablo "acidaque" procede del árabe $s a d a ̈ q$ y representa la cantidad que el marido aporta como dote al matrimonio. Entre los árabes preislámicos, la cantidad pagada por el novio se la quedaba el padre de la futura consorte, pero la reforma de Mahoma hizo que la dote pasara a ser propiedad exclusiva de la esposa con objeto de evitar la situación de desamparo en que quedaba cuando era repudiada o enviudaba, según algunas interpretaciones ${ }^{21}$.

La existencia de acidaque era uno de los requisitos básicos para la validez de los esponsales, y tanto la mención de la cantidad como la fijación de las condiciones de su pago constituían el punto esencial de las capitulaciones matrimoniales; porque lo normal, y así aparece en los manuales notariales, era que se aplazara la entrega o pago de una parte del acidaque. A nuestro modo de ver, ésta sería precisamente la situación que denotan los documentos resumidos: vínculos matrimoniales creados y acidaque negociado pero no percibido del todo. En tal caso, la marcha del marido - ¿y la disolución del matrimonio?- exigía la inmediata percepción de la parte todavía no cobrada y, con ello, pasaría a cumplir la función de paliar el desamparo económico provocado por el abandono ${ }^{22}$.

Además, ambos documentos aportan matices relativos a la situación y consideración de las mujeres. Frente a la conocida posibilidad que asistía al

20. 1385, IV, 13: AHN, Códs., n. ${ }^{\circ}$ 605-B, ff. 29-30. Tal vez esta orden tenga relación (aunque es difícil asegurarlo a causa del tiempo transcurrido) con otro escrito que la misma autoridad envió tres años después comunicando al regente de la bailía y al alamín de Miravet que Azmet Polpiq, ahora habitante de Zaragoza, se había quejado porque no había podido llevarse sus bienes de Miravet debido a que alguno de aquellos oficiales se los había embargado, y pidiéndoles que averiguaran lo que había de cierto en tal reclamación y que resolvieran el asunto (1388, V, 7: AHN, Códs., n. ${ }^{\circ}$ 605-13, ff. 208-209).

21. Los datos sobre los acidaques y, en general, sobre el matrimonio, los extraemos de A. CARMONA, «Aportación al estudio del contrato matrimonial en el occidente musulmán», Actas del XV Congreso de la UEAI, Utrecht, 1990 (copia anastática), con abundante bibliografía.

22. De hecho, en ninguno de los casos documentados podemos estar completamente seguros de que se debiera una parte del acidaque: el pacto de 1327 dice, en condicional, que si las mujeres "se volien pagar de lus açidachs", pudieran hacerlo de los bienes inmuebles que el castellán dejaba conservar a los moros huidos, y la orden de 1385 para detener a Azmel Polpiç y su yerno afirma, sin probarlo, que tales sarracenos se llevaban la ropa de casa y los acidaques de sus mujeres. Si acaso fuera cierto que hubiera una parte del acidaque no entregada, cabe añadir que los periodos de aplazamiento podían ser sumamente largos: tenemos un guiaje para Azmet Polpiç y varias personas más (entre las cuales, su mujer y tres hijos, ninguno con el nombre de Azmet, aunque no sea un dato terminante) en el que lo caracterizan como antiguo alamín de Miravet, hecho en 1368; suponiendo que fuera el mismo matrimonio y calculando unos pocos años desde su celebración, habrían pasado más de veinte cuando lo detienen por esa causa (el guiaje, en 1368, XI, 4: AHN, Códs., n. ${ }^{\circ}$ 603-B, ff. 26-27). De todas formas, parece ser que el pago de la dote llegaba a aplazarse sine die, incluso, según una práctica atestiguada con frecuencia, aunque ilegal (CARMONA, op. cit., p. 12). 
hombre para repudiar a su esposa, aquí, aunque de una forma un tanto marginal, aparecen las esposas en posesión de una cierta libertad: si quieren, pueden ir a vivir con sus maridos, y si no, pueden quedarse en los pueblos y cobrar sus acidaques; en otras palabras -aparte de que alguna de las fugas hubiera supuesto, a la vez, un repudio de la esposa, cosa que desconocemos-, lo interesante es que el enfoque del pacto deja la iniciativa en manos de las mujeres. Y a tenor del otro texto, Azmet Polpiç y su yerno permanecerían detenidos hasta que no se avinieran con sus mujeres, parientes o amigos sobre la parte del acidaque no entregada; no se menciona expresamente, sin embargo, ni al tutor legal ni a la autoridad musulmana competente, a no ser que en todos los casos se tratara de personas adultas o que entre los parientes ya se contemplara la posibilidad del tutor legal.

En otro orden de cosas, los jurados musulmanes consideraban indiscutible que, a tenor de la zuna, los juicios a los delincuentes sarracenos correspondían a oficiales musulmanes, miembros de su comunidad, y que debían desarrollarse conforme a aquella ley. Estas condiciones, empero, no se cumplían al menos desde el segundo cuarto del siglo XIV: la resolución de los delitos capitales se la reservaba directamente el castellán, quien designaba como juez a un representante cualificado de la orden, y la del resto de delitos le fue sistemáticamente discutida a las comunidades musulmanas en los casos que conocemos, cosa que provocó diversas y fundadas protestas por parte de los sarracenos ${ }^{23}$.

Siguiendo con apuntes de tipo procesal, recordemos que las apelaciones no existían en el mundo judicial islámico medieval. C. Barceló afirma que una de las características de la sarï’a en cuanto al procedimiento judicial "es la ausencia de autoridad: el juez puede retractarse de su propia sentencia, si se da cuenta de que ha cometido un error, y otro colega puede anular aquella decisión"; y Burns las interpreta como un "recurs al delegador", lo cual, aunque "no fos de cap manera el mateix que 1'apel.lació, podia haver-ho semblat als ulls del jurista cristià" ${ }^{24}$. Desde luego, Jaume II pensaba que la ley musulmana obligaba a admitir cualquier apelación contra una sentencia dada; y en aplicación de tal principio, mandó al administrador de las antiguas encomiendas templarias que procediera contra el alamín de Miravet, ya que este oficial, "indebidamente y contra zuna", no había aceptado la apelación inter-

23. 1323, VI, 20: AHN, EA, leg. $8175^{1}$, n. 10 (Carp. 636, n. ${ }^{\circ}$ 19): “[...] per çuna, los saralüns qui fan algun exçés degen ésser jutgats per l'alcadi et aljama del dit loch”; 1369, XI, 23: AHN, EA, leg. 8176, n. ${ }^{\circ} 13$ (Carp. 637, n. ${ }^{\circ} 28$ ): un sarraceno que "deu ésser jutjat per çuna". En el documento de 1323 se cita al cadí porque era el encargado de juzgar en Ascó, que es donde transcurren ambas protestas, pero la inclusión de la aljama junto a ese oficial la entendemos como un respaldo a la protesta y no en el sentido de que se encargara de juzgar realmente. Sobre el ejercicio de la administración de justicia, véase nuestro $L a$ sociedad..., pp. 968 y ss.

24. BARCELÓ, Un tratado..., p. XII; BURNS, L'Islam..., vol. I, p. 366, y, sobre el tema, pp. 363-367. 
puesta por un vecino de Benissanet ${ }^{25}$. En general, aunque no hayamos podido estudiarlo en detalle, es seguro que los mecanismos procesales cambiaron de manera radical bajo el dominio cristiano $^{26}$.

Y una vez hechos los juicios "segons lur çuna", los oficiales responsables castigaban "en azots et en multilacions de membres et encara a mort, segons les calitats dels crims et dels forfeyts", expresión relativamente amplia de las penas imponibles en el derecho penal islámico mientras el ejercicio práctico de la administración de justicia estuvo en manos de oficiales musulmanes. Esta mención de las penas puede adoptarse como una muestra de que la autoridad cristiana permitió a los musulmanes que siguieran aplicando el derecho penal musulmán en lo que respecta a las sanciones, cosa que para los cristianos no tenía importancia, mientras fuera eficaz, pero que para los musulmanes era una de las manifestaciones sociales más importantes del cumplimiento de la ley divina, dado que ese derecho, por figurar en el Corán, procedía directamente de Dios ${ }^{27}$.

Por último, cabe plantearse la posible matización de una zuna genérica mediante particularidades regionales o locales. Burns está seguro de que en el País Valencià existían "diferents usatges locals que es van conservar del regne islàmic precedent" y aporta como prueba diversas menciones de consuetudines. Los términos costum y usatge equivalen a normativa, fuero en el lenguaje medieval, y aunque las más de las veces fuera entonces una normativa local, no tiene por qué ser ésta la única interpretación. De todas formas, en general está probada la presencia y la fuerza de costumbres locales al menos en ciertas esferas del derecho musulmán ${ }^{28}$.

Desde luego, si a los privilegios o costumbres únicamente se alude en textos del siglo XIV, pueden referirse a la normativa acumulada durante el periodo de dominio cristiano; pero cuando las menciones corresponden a la segunda mitad del siglo XII o al inicio del XIII, fechas aún tempranas, hemos de dejar resquicios a la duda. Pues bien, en la misma capitulación de Tortosa,

25. 1312, IX, 26: ACA, R. 240, f. 81v.: el alamín de Miravet, Moferitg Abixander, había delinquido en su oficio, "in eo, quare, ut asseritur, appellationem emissam a quadam sententia per ipsum lata contra Mahometum Abinqeren, sarracenum de Biniçene, per eundem Mahometum, indebite el contra çunam admitere recusavit".

26. Burns afirma, siguiendo a Tyan, que "el cadi tenia un sol procediment per a les causes civils i criminals" (L'Islam..., vol. I, p. 381, n. 21), cosa que no era admisible en el sistema legal cristiano.

27. La cita relativa a las penas, en 1323, VI, 20: AHN, EA, leg. $8175^{1}$, n. ${ }^{\circ} 10$ (Carp. 636, n. ${ }^{\circ}$ 19); el comentario final procede del doctor Epalza.

28. BURnS, L'Islam..., vol. I, pp. 341 y ss.; sobre la presencia de usos locales: CARMONA, op. cit. y «Consideraciones sobre la pervivencia de la jurisprudencia andalusí en las épocas mudéjar y morisca», Actes du V'Symposium International d'Études morisques, Zaghouan, 1993, vol. I, pp. 209-222. 
Ramón Berenguer IV se refería a "sus costumbres y sus fueros" (1148); algo más tarde (1180), Alfons el Cast mandaba que se observara "aquella zuna y costumbre y fuero" concedido por el citado conde a los musulmanes de Tortosa, y unos años después (1216), se designaba a una persona para que fuera cadí "de toda la zuna de Tortosa" y se admitía que en caso de acusación fuera juzgado "según zuna y costumbre de los sarracenos". Con todo, la evidente debilidad de estos indicios obliga por ahora a dejar la particularidad regional como simple posibilidad ${ }^{29}$.

$* * *$

El análisis de la normativa jurídica islámica aplicada en el territorio se ve dificultado por la escasez de documentos y las demasiadas menciones que se hacen a la zuna de forma genérica, sin información asociada; pese a ello, nos parece que pueden avanzarse algunas conclusiones.

Por un lado, las relativamente comunes apelaciones a la zuna, en especial como base, fundamento o contexto de actuaciones diversas, demuestran su vigencia, la validez y continuidad de su aplicación, que fue seguramente mayor de lo que se colige del presente texto, debido al tipo de documentación que nos hemos visto obligados a utilizar.

No hay que olvidar, sin embargo, que los musulmanes se vieron inmersos desde la conquista en una nueva formación económicosocial. Esta situación comportaba el sometimiento a una presión sin precedentes sobre las actuaciones y comportamientos de aquellas comunidades, cuyas consecuencias forzosamente habrían de tener un reflejo práctico también en la normativa jurídica aplicada. A nuestro modo de ver, el efecto más importante fue la restricción de la validez de aquella normativa, una limitación que coincide en esencia con lo sucedido en otros campos, según dejamos apuntado al principio. En este sentido, las menciones que tienen origen en protestas de la comunidad musulmana no suponen otra cosa que una exigencia de comportamientos o intervenciones de acuerdo con la zuna, por lo que, sensu contrario, hemos de entender que no se estaba cumpliendo.

De hecho, la antigua legalidad no podía cubrir muchos de los requerimientos de la nueva situación, en especial los referidos a las relaciones con el

29. Capitulación de Tortosa: "Et quod levent ad illos alcaides de illos moros super lures usaticos et suos fueros in quantum tenent in manu, et quod sedeant honoratos in lures usaticos, sicut fuerunt in tempus de suos reges et non inde illos tragat nullus"; 1180, IX: ACA, Pergs., Alfons I, n. ${ }^{\circ} 299$ (tomado de ARGEMÍ, Els tagarins..., ap.): "illam zunam et consuetudinem et furum"; 1216, VI, 1: ACA, Pergs., Jaume I, n. 43 (tomado de ARGEMÍ, íb., ap.; ahora publicado asimismo por PAGAROLAS, Els templers..., ap., n. ${ }^{\circ}$ 4): "de omni zune Dertose", "secundum zunam et morem sarracenorum". Véase también, en relación a este tema, el texto que incluíamos en la n. 19, bien que corresponda ya al siglo XIV. 
mundo exterior a la comunidad estrictamente considerada. Ya desde un principio, los pactos de rendición previeron la posibilidad de pleitos entre miembros de ambas religiones y lo resolvieron dando la jurisdicción sobre cada litigante a jueces diferentes y ofreciendo a los vecinos musulmanes una serie de garantías que se movían desde la esfera judicial a la caracterización estrictamente política ${ }^{30}$.

Lógicamente, donde mejor se aprecian las limitaciones es en todo aquello en que intervenga el poder feudal: el tema de las herencias o el del ejercicio práctico de la jurisdicción criminal constituyen dos ejemplos evidentes. Por esa razón, son significativas -y previsibles, también- las posiciones de orden general que los sarracenos adoptaron en sus relaciones directas con las autoridades feudales, representantes cercanos e incómodos de la nueva formación económico-social impuesta. Hemos advertido tres posiciones.

En su trato con los feudales, las comunidades musulmanas complementaron a menudo la apelación a la ley islámica con otros conceptos representativos de la nueva realidad: así, cuando solicitaron que los "privilegios, libertades, zunas e inmunidades" que tenían concedidas les fueran confirmadas nuevamente (1318) o cuando protestaron porque una actuación del comendador era contraria al "dret comú de cristiana et encara contra lur çuna et contra encara tota bona rahó" $(1332)^{31}$.

Los sarracenos, incluso, debieron verse compelidos a olvidar su ley por

30. Capitulación de Tortosa: exigencia de testigos musulmanes en los juicios a miembros de esta comunidad ("et si habuerit aliquo mauro suspita de furtu vel de fornitio vel de alia mala facta, quod tangat illi iudicio vel castigamentum, quod sedeat ipso per testamentum de fideles et verdaderos mauros, et non credant christiano super illo moro"), protección por las actuaciones de otros reinos sarracenos ("Et si almoravites fecerint aliquod malum ad illos christianos [...] non prendant per inde nullo malo homines de Tortoxa") y una cierta inviolabilidad del domicilio, especialmente en el caso de búsqueda de sarracenos cautivos fugitivos, que debía limitarse a una casa y con la presencia de testigos ("Et si suspectaverit aliquo mauro, quod eum compariat moro vel mora captivo in sua causa, sine testimonio de mauro vel christiano, non cerchet sua casa. Et si habuerit testimonium, quod cerchet sua casa sola, et non de suo vicino"). Según la carta de seguridad de Ribera, si el sarraceno cautivo y fugitivo era de alguno de los castillos de la zona, su búsqueda podía extenderse a cuatro casas, pero sin repercusiones para el amo de la casa en que fuera encontrado ("Et si in aliquo de predictis castris fuerit captivus aliquit maurus et fugerit, requiratur solummodo in quatuor chasis de sarracenis et si in ipsis non fuerit inventus, non requiratur amplius in aliis earum domibus. Et si esset repertus in una ex quatuor chasis supradictis, non esse placitatus ille seinor de illa casa per ullam ren propter ihsunz captivum"); asimismo, se contempla una cierta limitación de la responsabilidad criminal a delitos propios, bien que la lectura del texto no sea muy segura ("non fuerit (?) si aliquis eorum requisitus vel inculpatus pro malefacta alterius, sed unusquisque respondat per se ipsum").

31. 1318, VI, 17: AHN, EA, leg. 8175 n. $^{\circ} 10$ (Carp. 636, n. ${ }^{\circ}$ 19): “privilegia, libertates, çunas et inmunitates" (las palabras pertenecen a la respuesta del castellán de Amposta, pero pensamos que deben corresponder a la petición misma de la aljama de Ascó); 1332, IX, 24: AHN, EA, leg. 8175¹ , n. 11 (Carp. 636, n. $\left.^{\circ} 20\right)$. 
completo, ya que fundaron una protesta en el "prevaletge $e$ usança e costuma 
antigua e covineça que fo feyta a els" por el conde Ramón Berenguer IV (1369) o reclamaron y se quejaron porque un juicio había sido hecho "més per violència o per força o per poder que per dret ni per rahó" $(1323)^{32}$.

$\mathrm{Y}$, por supuesto, las comunidades musulmanas estuvieron obligadas a conocer e integrarse en el mundo legal cristiano, pues tales eran las normas dominantes, hasta el punto de que más de una vez debieron argumentar que su apelación no era "frustatòria", sino que había sido hecha "segons dret et bona usanza de tota Catalunya" $(1323)^{33}$.

En definitiva, la ley islámica bajo el dominio cristiano se convirtió en un corpus de eficacia reducida: mantuvo la vigencia teórica pero, al disminuir los temas a cuya resolución podía aplicarse, su validez práctica se vio progresivamente limitada; las restricciones afectaron de manera especial a todo aquello que supusiera tratos o contactos con el poder feudal y se debieron precisamente a la presión e intervenciones de ese poder.

\section{RESUMEN}

La Ribera d'Ebre (Tarragona) es una de las comarcas conquistadas por el conde barcelonés Ramón Berenguer IV a mediados del siglo XII. Pese a la conquista cristiana, muchos musulmanes decidieron permanecer en el territorio, igual que sucedió en otros lugares del entorno tortosino e ilerdense. Esto explica que la documentación procedente de la zona contenga alusiones a la normativa jurídica islámica que ahí se aplicaba o debiera haberse aplicado. Hemos recogido notas relativas a herencias, acidaques, apelaciones, penas imponibles y justificación documental de las posesiones, y hemos observado la posibilidad de particularidades regionales de aquella legalidad. El análisis de estas notas permite concluir que la ley islámica se convirtió en un corpus de eficacia reducida bajo el dominio cristiano, dado que se restringieron los temas a cuya resolución podía aplicarse, y que las limitaciones se debieron a la presión y a las intervenciones del poder feudal.

32. 1323, VI, 20: AHN, EA, leg. $8175^{1}$, n. $^{\circ} 10$ (Carp. 636, n. ${ }^{\circ}$ 19) (bien que podamos entender que tal concesión ya incluía las leyes sarracenas, lo interesante es que no las mencionen de forma explícita); 1369 , XI, 23: AHN, EA, leg. 8176, n..$^{\circ} 13$ (Carp. 637, n. ${ }^{\circ}$ 28). Aún podemos añadir la confirmación de conventiones, pacta, privilegia, libertates, usus et consuetudines de Asco por parte del Gran Maestre del Hospital, obligando al castellán y comendadores a respetarlos, aunque tampoco sean términos utilizados directamente por la comunidad musulmana; véase 1347, VIII, 8: ACA, R. 4835, ff. 7v.-20v. 


\begin{abstract}
About Islamic Law applied on the Muslims from 'La Ribera d'Ebre'. 'La Ribera d'Ebre' (Tarragona) is one of the districts conquered by the count of Barcelona Ramón Berenguer IV by the middle of the XII century. Despite the Christian conquest, many Muslims decided to remain in the territory, as it also happened in other places near Tortosa and Lerida. This explains that the documentation coming from this area contains allusions to the Islamic Law, which was applied there or should have been applied. We have collected notes on inheritances, 'acidaques', appeals, penalties -they could impose- and documents to justify possessions, and we have observed the possibility of regional particularities of that legality. The analysis of there notes allows to conclude that the Islamic Law became a corpus of reduced effectiveness under the Christian domain, since the topics to which the resolution could be applied were restricted, and that the limitations were due to the pressure and the interventions of the feudal power.
\end{abstract}

